\title{
Applying MORT to the analysis of Tabasco's flooding
}

\author{
J. Santos-Reyes, R. Alvarado-Corona, S. Olmos-Peña \\ \& R. Tejeida-Padilla \\ Safety; Accident, Risk \& Reliability Analysis Research Group, \\ Systems Engineering Department, SEPI-ESIME, IPN, Mexico
}

\begin{abstract}
Natural disasters are increasing alarmingly worldwide in recent years. They have killed millions of people, and adversely affected the life of at least one billion people. Given this, natural disasters present a great challenge to society today concerning how they are to be mitigated so as to produce an acceptable risk is a question which has come to the fore in dramatic ways recently. The paper addresses the following question: what could be learnt from natural disasters? The paper presents some preliminary results of the analysis of Tabasco's flooding in Mexico, by the application of the MORT technique. In November 2007 the State of Tabasco was flooded by $80 \%$ and it is believed that al least one million people were left homeless. On the other hand, the MORT technique may be regarded as a structured checklist in the form of a complex 'fault-tree' model that is intended to ensure that all aspects of an organization's management are looked into when assessing the possible causes of an incident. Moreover, the MORT has been applied extensively to the analysis of past failure of sociotechnical systems; this is the first time that it has been applied to the case of natural disasters. A number of organizational failures have been highlighted by the model. It is hoped that by conducting such analysis lessons can be learnt so that the impact of natural disasters such as Tabasco's flooding can be mitigated in the future.
\end{abstract}

Keywords: risk, disaster, MORT. 


\section{Introduction}

Natural disasters are increasing alarmingly worldwide in recent years. They have killed millions of people, and adversely affected the life of at least one billion people. On 19 September 1985, Mexico City suffered the devastating effects of an earthquake, which left 5,000 people dead and destroyed 48,000 houses. It is thought that the reconstruction took about two years [1]. On 30 September 1993, an earthquake occurred in Maharashtra, India. It is believed 8,000 people lost their lives and about 230,000 houses were seriously damaged or collapsed in the earthquake. About 30,000 affected families had to stay in temporary houses for about four years [2]; it took five years to complete the reconstruction work. On 17 January 1995 about 6,400 people were killed in the Kobe earthquake in Japan; it is believed that about 134,000 houses were damaged and 31,000 affected families had to live in temporary refugees [3, 4]. On 17 August 1999, the massive earthquake of Turkey took the lives of more than 9,000 people [5]. The Kashmir earthquake of 8 October 2005 struck both Pakistan and India and left more than 50,000 people dead in the two countries [6]. More recently, the deadliest earthquake in nearly 30 years occurred in L'Aquilla, Italy. The 6.3 magnitude earthquake struck shortly after 3:30 local time on 5 April 2009 leaving dozens dead and thousands homeless [7].

On the other hand, hurricanes Katrina, Rita and Stan that occurred in 2005 have shown how vulnerable countries could be to such events. For instance, Hurricane Katrina caused an estimated $\$ 35$ to $\$ 60$ billion in damage and resulted in at least 1000 deaths in the United States alone [8]. Moreover, it is believed that 2008 was one of the most devastating years on record; it has been estimated that more than 220,000 people were killed by natural disasters in this year alone [9]. The most devastating in terms of human fatalities was Cyclone Nargis, which lashed Burma in May, killing more than 135,000 people and leaving more than one million homeless; a few days later an earthquake shook China's Sichuan province, leaving 70,000 dead, 18,000 missing and almost five million homeless; around 1,000 people died in a severe cold snap in January in Afghanistan, Kyrgystan and Tajikistan, while 635 perished in August and September in floods in India, Nepal and Bangladesh; Typhoon Fengshen, killed 557 people in China and the Philippines in June, while earthquakes in Pakistan in October left 300 dead; Six tropical cyclones also slammed into the southern United States, including Ike which, with insured losses of 10 billion dollars, was the industry's costliest catastrophe of the year [9].

In addition, trends suggest that the impact of natural disasters is intensifying, with an increasing effect on poor nations largely due to growing populations and a greater vulnerability to natural hazards. Researchers, governmental and nongovernmental organizations (NGO) have published a vast amount of reports and publications on the management of natural disasters; see for example, [10-15].

The above stresses the importance of prevention, mitigation and preparedness including evacuation planning in order to limit the impact of natural disasters. Disaster prevention includes all those activities intended to avoid the adverse impact of natural hazards (e.g. a decision not to build houses in a disaster-prone 
area). Mitigation, on the other hand, refers to measures that should be taken in advance of a disaster order to decrease its impact on society (e.g. developing building codes). Finally, disaster preparedness includes pre- and post- emergency measures that are intended to minimize the loss of life, and to organize and facilitate timely effective rescue, relief, and rehabilitation in case of disaster (e.g. organizing simulation activities to prepare for an eventual disaster relief operation). Given the above, natural disasters present a great challenge to society today concerning how they are to be mitigated so as to produce an acceptable risk is a question which has come to the fore in dramatic ways in recent years. This paper addresses the following issue: what could be learnt from natural disasters? The paper presents some preliminary results of the application of the Management Oversight Risk Tree (MORT) model to the case of Tabasco's flooding in Mexico. The MORT model has been used extensively as a tool to analyze past failure of socio-technical systems; i.e. accidents that have occurred in industrial sectors such as nuclear, aviation, railways, etc. A number of organizational deficiencies have been highlighted by the model. It is hoped that by applying such models lessons can be learnt so that the impact of natural disasters such as Tabasco's flooding can be mitigated in the future.

\section{The MORT model}

The Management Oversight and Risk Tree (MORT) is an analytical procedure for determining causes and contributing factors. In MORT, accidents are defined as "unplanned events that produce harm or damage, that is, losses" [16]. Losses occur when a harmful agent comes into contact with a person or asset. This contact can occur either because of a failure of prevention or, as an unfortunate but acceptable outcome of a risk that has been properly assessed and acted-on (a so-called "assumed risk"). MORT analysis always evaluates the "failure" route before considering the "assumed risk" hypothesis. In MORT analysis, most of the effort is directed at identifying problems in the control of a work/process and deficiencies in the protective barriers associated with it. These problems are then analyzed for their origins in planning, design, policy, etc. In order to use MORT key episodes in the sequence of events should be identified first; each episode can be characterized as: $\{1\}$ a vulnerable target exposed to; $\{b\}$ an agent of harm in the; $\{c\}$ absence of adequate barriers.

The "Barrier analysis" is intended to produce a clear set of episodes for MORT analysis. It is an essential preparation for MORT analysis. The barrier analysis embraces three key concepts, namely: $\{a\}$ "energy"; $\{b\}$ "target"; and \{c\} "barrier". "Energy" refers to the harmful agent that threatens or actually damages a "Target" that is exposed to it. "Targets" can be people, things or processes - anything, in fact, that should be protected or would be better undisturbed by the "Energy". In MORT, an incident can result either from exposure to an energy flow without injuries or damage, or the damage of a target with no intrinsic value. "Barrier" part of the title refers to the means by which "Targets" are kept safe from "Energies". 


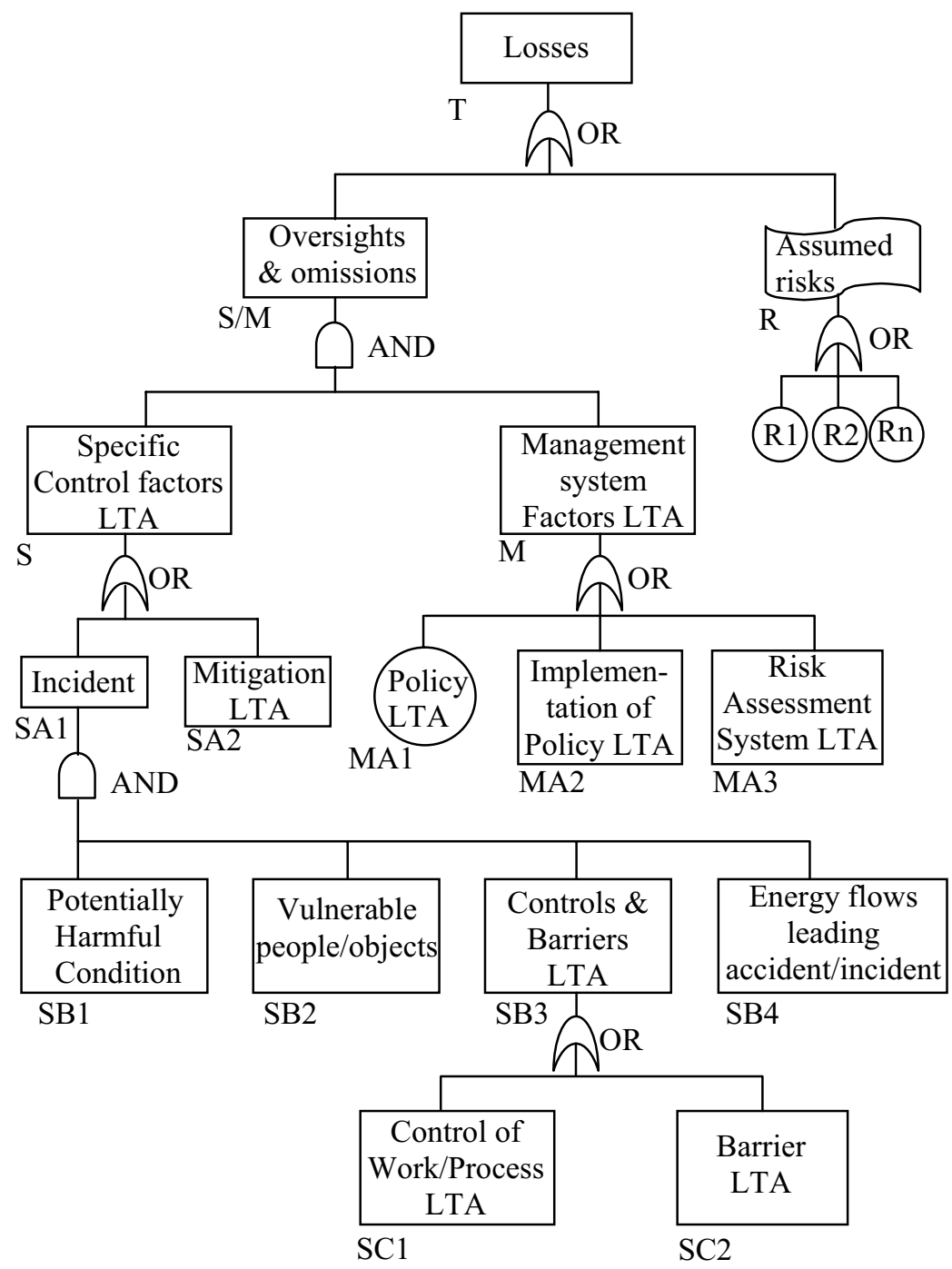

Figure 1: $\quad$ The MORT structure [16].

Figure 1 shows the basic MORT structure. The top event in MORT is labelled "Losses", beneath which are its two alternative causes; i.e., $\{1\}$ "Oversights and Omissions", $\{2\}$ "Assumed risks". In MORT all the contributing factors in the accident sequence are treated as "oversights and omissions" unless they are transferred to the "Assumed risk" branch. Input to the "Oversights and Omissions" event is through and AND logic gate. This means that problems manifest in the specific control of work activities, necessarily involve issues in the management process that govern them. On the other hand, the "Specific and 
Management" branches are regarded as the two main branches in MORT (see Figure 1). Specific control factors are broken down in to two main classes: $\{\mathrm{a}\}$ those related to the incident or accident (SA1), and $\{\mathrm{b}\}$ those related to restoring control following an accident (SA2). Both of them are under an OR logic gate because either can be a cause of losses.

\section{Tabasco's flooding}

The State of Tabasco is located at the Southern region of Mexico (see Figure 2). It has an estimated population of 1,891,892 inhabitants. The State is divided into two major regions; i.e., the 'Grijalva' region and the 'Usumacinta' region. ('Grijalva' and 'Usumacinta' are the names of the two biggest rivers in Mexico and both of them flow across the State of Tabasco). The 'Grijalva' region consists of 12 municipalities (i.e., A, C, D, E, F, G, H, I, J, L, and M) as shown in Figure 2. On the other hand, the 'Usumacinta' region consists of 6 municipalities; i.e. B, N, O, P, Q, and $\mathrm{K}$ as shown in Figure 2. The disaster occurred in November 2007 and it has been regarded as one of the worst that has hit the State for more than 50 years. It is believed that $80 \%$ of the State has been flooded and more than one million people have been left homeless; see Figure 2.

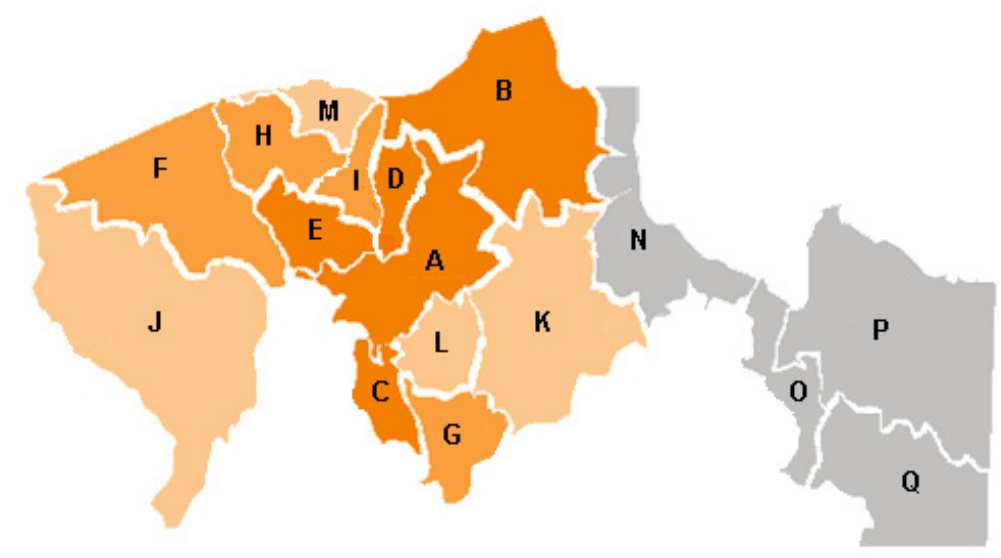

\begin{tabular}{|c|c|c|c|c|c|c|c|c|c|}
\hline Municipalities & A & B & C & D & E & F & G & H & I \\
\hline $\begin{array}{c}\text { Flooding } \\
\text { (\%) }\end{array}$ & 80 & 80 & 60 & 50 & 60 & 20 & 40 & 30 & 60 \\
\hline Municipalities & J & K & L & M & N & O & P & Q & \\
\hline $\begin{array}{c}\text { Flooding } \\
(\%)\end{array}$ & 40 & 40 & 60 & 40 & 60 & 20 & 30 & 30 & \\
\hline
\end{tabular}

Figure 2: \% Flooded municipalities of the State of Tabasco [17]. 


\section{The analysis}

Figure 3 and table 1 show the "Barrier" analysis for Tabasco's flooding disaster. It can be seen that only one "Energy flow" (i.e. 'water') has been considered for the analysis. More "energy flows" may be considered for future analysis.

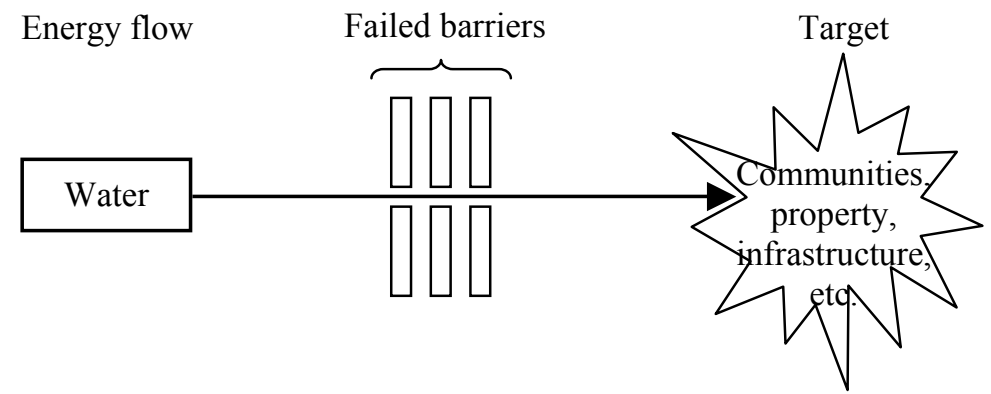

Figure 3: Graphical representation of "Energy flow", "Barriers" and the "Target".

Table 1: $\quad$ Barrier analysis for Tabasco's flooding.

\begin{tabular}{|c|c|c|}
\hline "Energy flow" & "Target" & "Barrier" \\
\hline Water & $\begin{array}{c}\text { Communities, property, } \\
\text { infrastructures (schools, } \\
\text { hospitals), etc. }\end{array}$ & $\begin{array}{c}\text { Physical barriers against flooding, } \\
\text { hydraulic controls, etc. }\end{array}$ \\
\hline
\end{tabular}

On the other hand, Figures 4 to 7 illustrate some branches of the MORT chart; Table 2 presents some of the findings highlighted by the model.

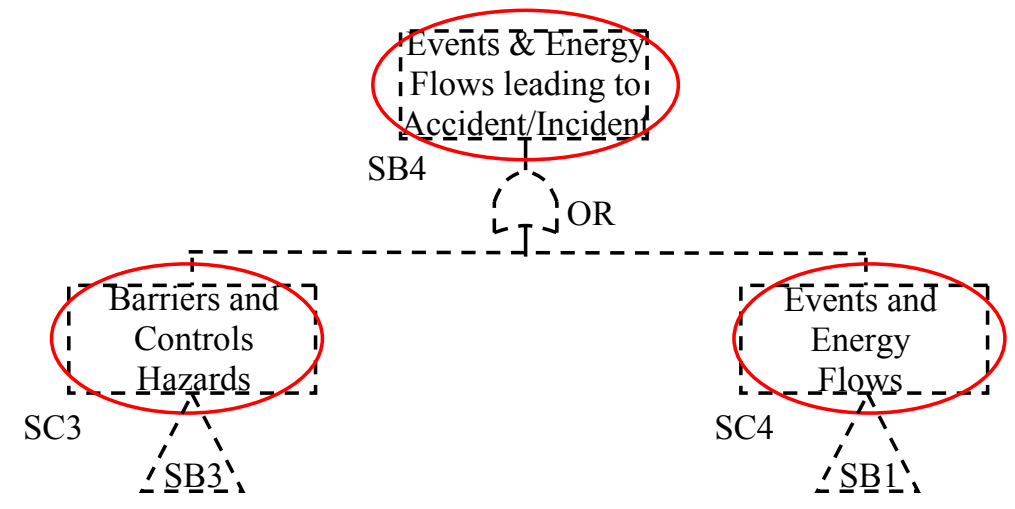

Figure 4: Branch SB4- "Events and energy flows leading to accident/incident" (red: problems that contributed to the outcome). 


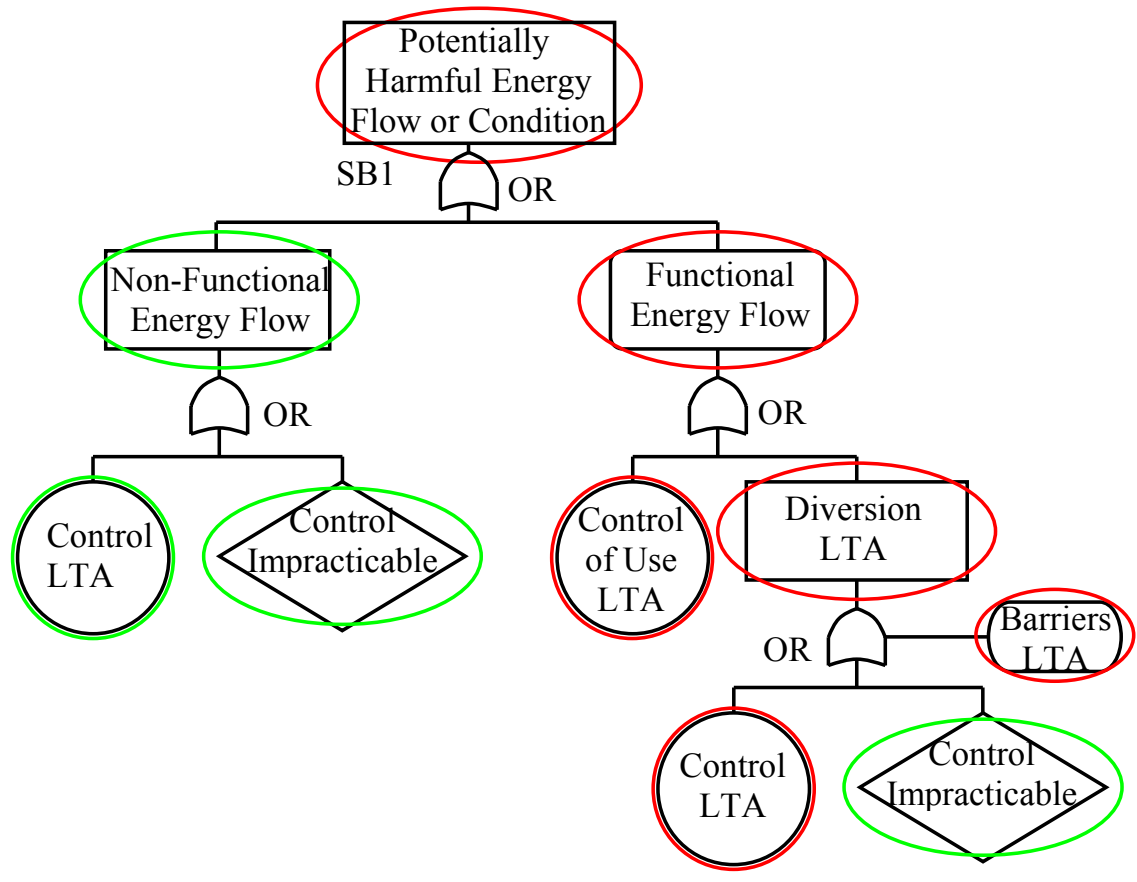

Figure 5: Branch SB1- "Potentially harmful energy flow or condition". (Red: problems that contributed to the outcome. Green: judged to be satisfactory).

\section{Conclusions and future work}

Some preliminary findings of the flooding of the State of Tabasco, Mexico have been presented. The approach has been the application of the MORT model. The analysis has shown that the MORT technique has the potentiality to be used to identify organizational failures to the case of natural disasters. It should be pointed out that the MORT has been used extensively to the analysis of past failures of socio-technical systems (i.e., petrochemical, transport, etc.); this is the first time that it has been applied to the case of natural disasters. However, more work is needed in order to draw some final lessons from Tabasco's flooding; i.e. more 'energy flows' should be investigated. Moreover, the model can be applied to the case of earthquakes. It is hoped that by conducting such analysis lessons can be learnt so that the impact of natural disasters can be mitigated in the future. 


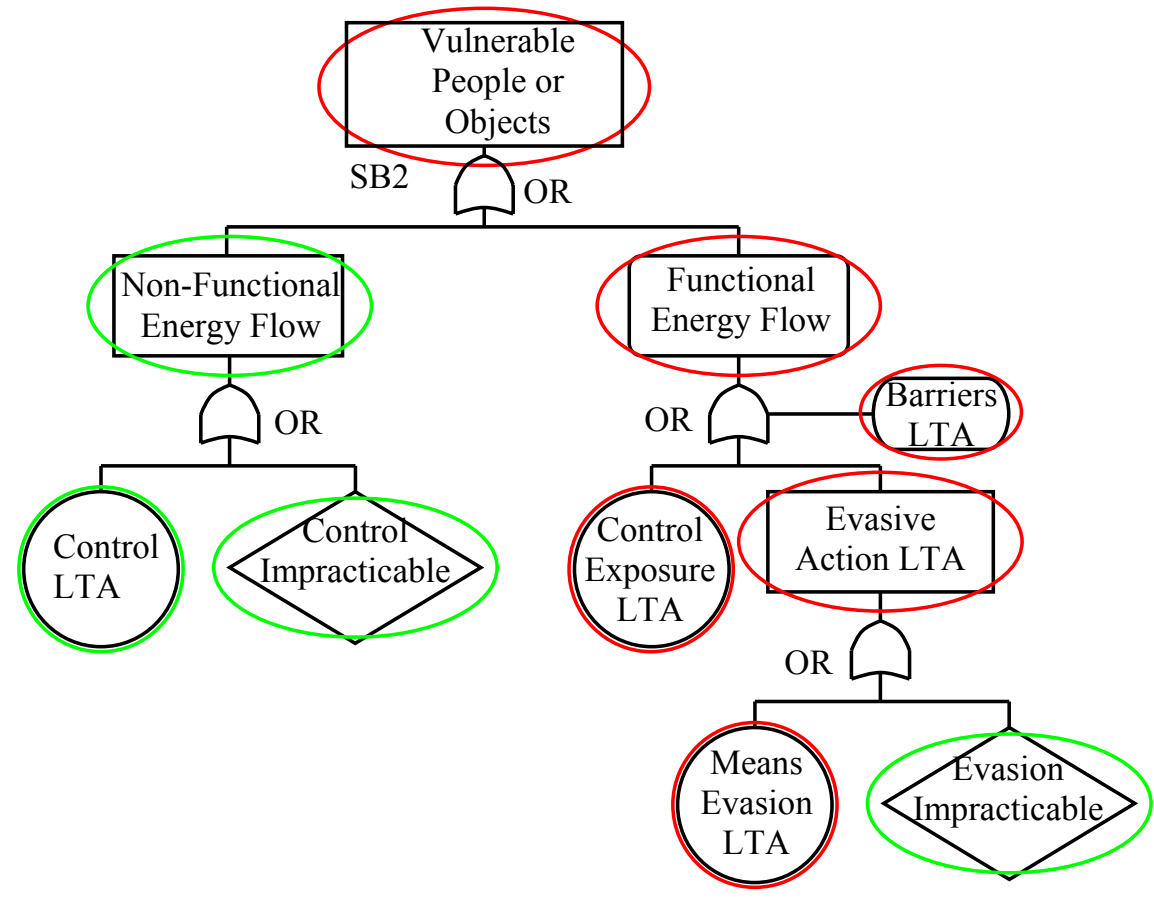

Figure 6: Branch SB2- "Vulnerable People or Objects". (Red: problems that contributed to the outcome. Green: judged to be satisfactory).

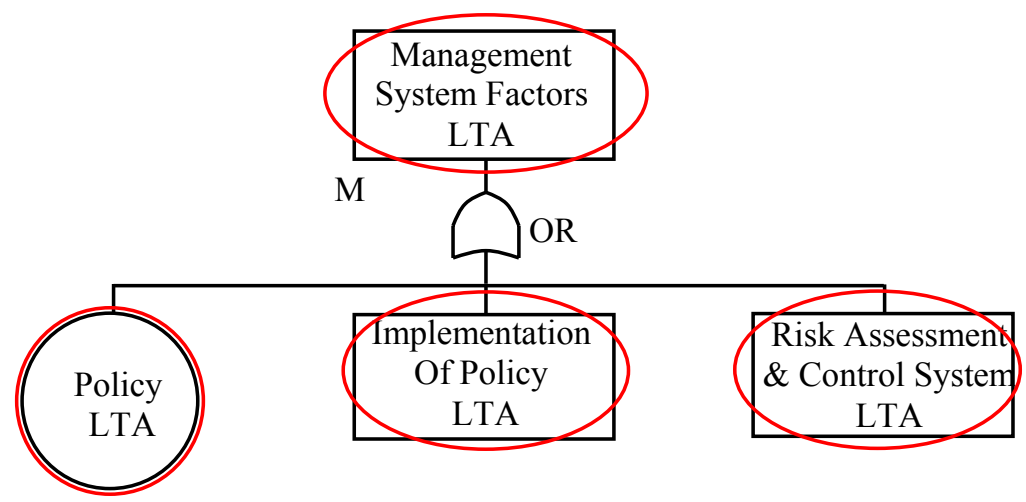

Figure 7: $\quad$ Branch M- "Management System Factors". (Red: problems that contributed to the outcome). 
Table 2: $\quad$ Some of the findings highlighted by MORT.

1. Poor attitude from top management; i.e. Federal and local government.

2. A flood risk assessment was not conducted, even if conducted it did not highlight these scenarios.

3. None in the management responsible for the communities' safety.

4. Lack of training; i.e. people did not know what/how to evacuate safely under such circumstances.

5. Lack of support from top and local government (Federal, local)

6. No internal checks and monitoring.

7. No independent checks/monitoring.

8. Lack of effective coordination amongst the key organizations involved, for example, in the evacuations process (i.e., federal, local, government, etc).

9. Lack of an effective emergency plan for such scenarios; for example, it took several days to evacuate and rescue survivors.

\section{Acknowledgements}

This project was funded by SIP-IPN under the following grant: SIP-IPN: No20090920.

\section{References}

[1] EERI, Impressions of the Guerrero-Michoacán, Mexico, Earthquake of 19 September 1985: A Preliminary Reconnaissance Report, EERI-NAS, San Francisco, CA, USA, 1985.

[2] MERDP, "Marathawada earthquake: efforts at participatory rehabilitation and the role of community participation", Report No. 4, Government of Maharashtra, Mumbai. India, 1998.

[3] KAP, The Kobe action plan", paper presented at International Forum of Disaster Management of Citizens and NGO, Kobe (in Japanese: Shimin Sakai o Tsukuru), 2001.

[4] Shaw, R. and Goda, K., From disaster to sustainable civil society: the Kobe experience, Disaster, Vol. 28, No. 1, pp. 16-40, 2004.

[5] Jalali, R., Civil society and the state: Turkey after the earthquake, Disasters, Vol. 26, No. 2, pp. 120-39, 2002.

[6] BBC, Quake survivors 'still need aid'. BBC NEWS: http://news.bbc.co.uk/go/pr/fr/-/2/hi/south_asia/4890252.stm, (5/04/09).

[7] Owen, R. \& Bannerman, L., Italy in desperate race to save the buried after the earthquake, The Times, UK, 2009.

[8] Barrett, J., Pay now to save later. Newsweek - Gulf hurricanes 2005, URL:http://newsweek.com (26/09/2005).

[9] The Times, Natural disasters 'killed more than 220,000' in 2008. The Times. UK, 2009. 
[10] ISDR, Living with Risk: A Global Review of Disaster Reduction Initiatives, United Nations, Geneva, 2002.

[11] Kreimer, A. and Arnold, M., Managing Disaster Risk in Emerging Economies, World Bank, Washington, DC., USA, 2000.

[12] Freeman, P.K., Martin, L.A., Mechler, R., Warner, K. and Hausmann, P., Catastrophes and Development: Integrating Natural Catastrophes into Development Planning, working papers series no. 4, World Bank, Washington, DC., USA, 2002.

[13] ECLAC, Manual for Estimating the Socio-economic Effects of Natural Disasters, United Nations, Hewitt, K. (1997), Regions of Risk: A Geographical Introduction to Disasters, Addison-Wesley Longman, Harlow, 1991.

[14] Colombo, A.G. and Vetere-Arellano, A. L., "Dissemination of lessons learnt from disasters, NEDIES workshop, Ispra, 2002.

[15] Benson, C. and Clay, E.L., Developing countries and the economic impacts of natural disasters, in Kreimer, A. and Arnold, M. (Eds), Managing Disaster Risk in Emerging Economies, World Bank, Washington, DC, pp. 11-21, 2000.

[16] NRI, MORT user's manual. For use with the management Oversight \& Risk Tree analytical logic diagram, NRI, 2002.

[17] Tabasco, Regiones del Estado, http://www.tabasco.gob.mx/estado/georegiones.php (5/09/2008). 